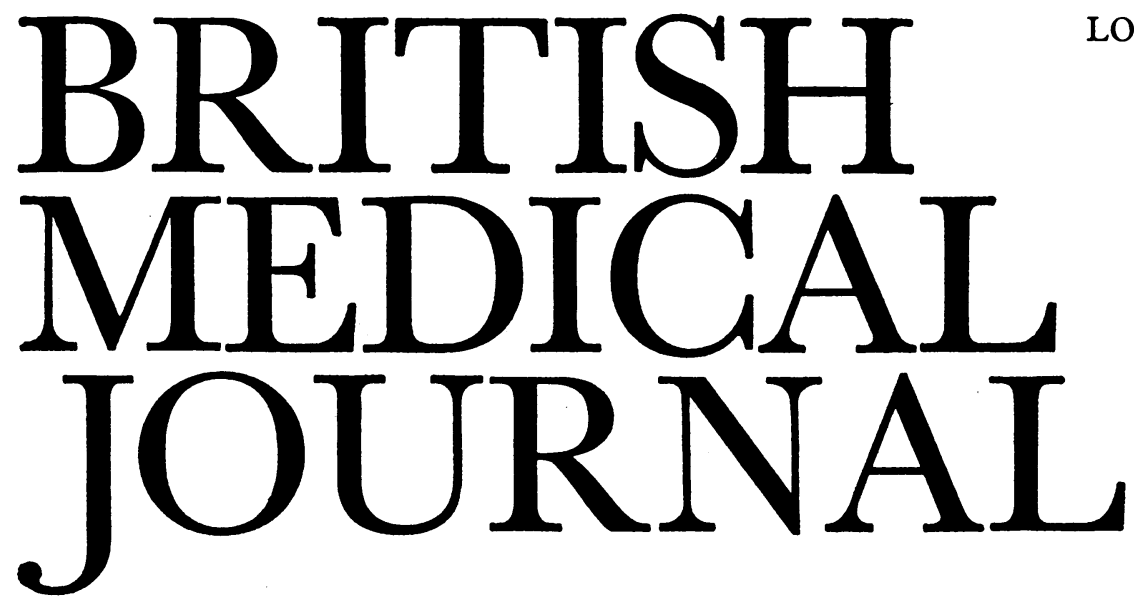

LONDON, SATURDAY 15 NOVEMBER 975

\title{
What are haemorrhoids?
}

When two names are applied to a single condition they usually emphasise distinct clinical features. The Greek word haemorrhoid focuses attention on the discharge of blood; indeed, the vessels concerned are named for this propensity. The middle English term piles is of uncertain origin but may be cognate with the Latin pila, meaning a ball or a pillar, suggesting the protrusion of a mass.

Haemorrhoids have long been accepted to be tortuous, dilated, submucous anal veins resulting from congestion. Morgagni ${ }^{1}$ attributed them to increased pressure resulting from the upright human posture. Local venous congestion has been ascribed to pressure upon the draining veins by masses such as constipated faeces or a pregnant uterus, while general congestion occurs in portal hypertension. The mass of dilated veins and overlying mucosa is thought to be extruded during defaecation, causing prolapse, while localised trauma causes bleeding. The usual position of haemorrhoids at 3, 7, and 11 o'clock when viewed from below with the patient in the lithotomy position was explained by $\mathrm{Miles}^{2}$ as resulting from division of the right main branch of the superior rectal artery into anterior and posterior branches while the left main branch continues undivided.

Other explanations for piles have been proposed. Hunter ${ }^{3}$ compared them with cavernous tissue and Cruveilhier ${ }^{4}$ and others noted a similarity to erectile tissue. Virchow ${ }^{5}$ thought them to be haemangiomatous, and they have recently been likened to cavernous haemangiomas. ${ }^{6}$ The demonstration by German workers ${ }^{78}$ of arteriovenous communications suggested erectile properties and offered an explanation for the bright red colour of the blood lost from haemorrhoids. It has also been suggested that haemorrhoids result from prolapse of the anal lining. Parks ${ }^{9}$ likened third degree piles to a sliding hernia. Patey ${ }^{10}$ thought that the proctoscopic appearance of piles resembled "exaggerated protrusions of the bowel lining at the anorectal junction."

Thomson ${ }^{11}$ has recently undertaken a painstaking reappraisal of the nature of piles. He carried out intravascular injection studies in 95 cadavers including 10 infants and 3 adolescents, supported by clinical studies including the proctoscopic appearances in the normal anal canal and in haemorrhoid sufferers. Venous injections showed the presence of fusiform, saccular, or serpiginous dilatations in all of 50 adult cadavers and in 8 of 10 infants, confirming the findings of Sappey ${ }^{12}$ and others that these dilatations are constant and normal findings. The histological appearances of haemorrhoidectomy specimens did not, in Thomson's opinion, differ appreciably from the normal anorectal submucosa; and he concluded that venous congestion need not be invoked to account for the vascular dilatations seen in haemorrhoidsthey are not seen with abnormal frequency in sufferers from portal hypertension, ${ }^{13}$ while congestion cannot explain the frequent occurrence of a solitary pile. Arterial injections confirmed the presence of arteriovenous connections, but the distribution of the superior rectal artery as described by Miles could not be substantiated.

Histological examination of the anorectal submucosa showed that it was complex, with a rich venous plexus supported by a network of elastic tissue and by smooth muscle fibres. ${ }^{14}$ Viewed through the proctoscope, the bulky anorectal lining was seen to be discontinuous, being disposed in three cushionlike masses at the usual sites of primary piles and closing to form a triradiate slit. The similarity between the structure of these cushions and haemorrhoidectomy specimens led Thomson to believe that haemorrhoids are merely displaced and prolapsed cushions, the extrusion resulting from disruption of the supporting tissues previously noted by Gass and Adams. ${ }^{15} \mathrm{He}$ found that only 5 of 66 haemorrhoid sufferers confidently remembered bleeding as the initial symptom and suggests that haemorrhage is secondary to prolapse, producing congestion.

If piles are a sliding down of part of the anal canal lining they should appear indistinguishable from rectal prolapse except for producing three discrete swellings; and if bleeding occurs only secondary to prolapse, unprolapsed piles should not bleed. Nevertheless, proctologists look for congested masses bulging into the lumen as a diagnostic feature of piles, whether or not they are prolapsed. If Thomson is correct, first degree piles that present with bleeding in the absence of prolapse should not occur, and anyway could not be diagnosed because they would seem identical to normally placed anal cushions. If congestion is not an important cause of piles and does not contribute to the presence of venous spaces, it is not clear what causes the capillary dilatation that appeared to be the source of bleeding in many specimens.

Finally, even if we do accept the anatomical origin of piles, it will doubtless remain contentious whether prolapse occurs from abnormal forces extruding previously normal structures or whether the anal cushions increase in size from vascular 
congestion or haemangiomatous dilatation, making them more likely to displacement. Nevertheless, this careful study successfully questions orthodox views on the cause of haemorrhoids.

${ }^{1}$ Morgagni, J B, Seats and Causes of Diseases, vol 2, letter 32, article 10, translated by Benjamin Alexander, p 105. London, A Millar, 1769.

2 Miles, W E, Surgery, Gynecology, and Obstetrics, 1919, 29, 497.

${ }^{3}$ Hunter, J, Cases in Surgery. Hunterian Manuscripts (W Clift's transcript), vol 2, p 95. (Royal College of Surgeons MS 49e 10.)

4 Cruveilhier, J, Traité d'Anatomie Pathologique, 5 vols. Paris, Baillière, 1849-64.

5 Virchow, R, Die Krankhaften Geschwülste. Berlin, Hirschwald, 1863.

6 Morson, B C, and Dawson, I M P, Gastrointestinal Pathology, p 617. Oxford, Blackwell, 1972.

7 Staubesand, J, Stelzner, F, and Machleidt, H, Morphologisches fahrbuch, 1963, 104, 405.

8 Stelzner, F, Deutsche medizinische Wochenschrift, 1963, 88, 689.

9 Parks, A G, British fournal of Surgery, 1956, 43, 337.

10 Patey, D, British Medical fournal, 1972, 2, 712.

11 Thomson, W H F, British fournal of Surgery, 1975, 62, 542.

12 Sappey, $\mathrm{Ph}$ C, Traité d'Anatomie Descriptive, 2nd edn, vol 4, p 276. Paris, Delahaye, 1972

${ }^{13}$ Hunt, A H, A Contribution to the Study of Portal Hypertension, $\mathrm{p} 61$. Edinburgh, Livingstone, 1958.

14 Treitz, W, Vierteljahrschrift für Praktische Heilkunde (Prague), 1853, 1,

113.
15 Gass, O C, and Adams, J, American Fournal of Surger'y, 1950, 79, 40.

\section{The problem of rosacea}

Imagine being asked to invent a new disease-one designed to cause as much embarassment to the patient as possible. The specification might run like this : first select a group of people who are already rather sensitive, with a tendency to blush easily. Next, use the only area of skin which cannot be hidden from view-the face. Cover this with a bumpy redness. Add a scattering of pustules and a tendency for the nose to grow red and clown-like. Build in a popular myth that these changes are due to heavy drinking, so that an element of mockery will surround the patient wherever he goes. Finally, devise a treatment, such as using topical fluorinated steroids, which patients are keen to use as it seems to help in the short term but which actually makes the face much redder in the long run.

The specification is, of course, that of rosacea; but its treatment is not simply a matter of getting rid of a few rather amusing pustules. Patients with rosacea may be quite seriously depressed, ${ }^{1}$ and rosaceous keratitis (found in 19 of a consecutive series ${ }^{2}$ of 57 patients referred to a skin clinic) may lead to permanent impairment of vision. ${ }^{3}$

Luckily the tetracyclines provide a treatment which is highly effective against the pustular and papular elements of the disease. The dose needed is small, usually $250 \mathrm{mg}$ twice a day, but as in acne treatment may need to go on for several months. In one series ${ }^{4} 68$ patients whose skin had cleared with tetracycline stopped treatment after six months: 17 relapsed immediately, and the overall relapse rate was $69 \%$ for patients followed up for a maximum of four years. Patients with rosacea tend to be older than those with acne, in whom this type of treatment has seemed to be singularly free from severe systemic side effects, ${ }^{56}$ and it is reassuring that in a recent survey $^{7}$ of 246 patients, including 38 with rosacea, on low dosage long-term tetracyclines, no clinically significant abnormalities of liver or kidney function were found, though these do occur with higher doses.

The eye changes in rosacea are of two main kinds. Blepharitis and a suffused conjunctivitis are common and non-specific, while rosaceous keratitis is highly specific. There is a small but growing body of evidence that this keratitis may also respond to systemic tetracyclines, ${ }^{8}{ }^{9}$ and that relapses may occur when treatment is stopped, ${ }^{4}$ suggesting perhaps that the mechanisms underlying the eye changes may be similar to those in the skin. Ampicillin is also helpful in rosacea, ${ }^{10}$ but it is still not established that the beneficial effect of antibiotics is due to bacterial suppression. The microbiology of rosacea may well be as unexpectedly complex as that of acne. ${ }^{11}$

It would be nice to pretend that our current treatment regimens are solidly based on a full understanding of the cause of the disease, but this is not so. Theories tend to run ahead of facts in rosacea, as in so many fields in medicine. Indeed Sneddon, in the first proper trial to confirm the value of tetracycline in rosacea, commented" that "there must be few diseases which cause more emotional flushing in the supporters of the various theories of causation than rosacea." Borrie $^{12}$ had described these hypotheses as varying "from something alkaline in the stomach to something horrid in the cowshed." Marks ${ }^{1}$ took on the task of critically re-examining the main ideas in the light of his experience of 92 patients with rosacea; none could be supported. Even the latest opinions, invoking vasoactive substances such as bradykinin, have little evidence in their favour. There are still vacancies in the cowshed.

${ }^{1}$ Marks, R, British fournal of Dermatology, 1968, 80, 170.

2 Starr, P A J, and Macdonald, A, Proceedings of the Royal Society of Medicine, 1969, 62, 9.

3 Goldsmith, A J B, British Fournal of Dermatology, 1953, 65, 448.

4 Knight, A, and Vickers, C F H, British fournal of Dermatology, 1975, 93, Suppl 2, 12.

${ }^{5}$ Gilgor, R S, North Carolina Medical fournal, 1972, 33, 331.

${ }^{6}$ Osment, L S, and Hammack, W J, Southern Medical fournal, 1970, 63, 1156.

7 Delaney, T J, Leppard, B J, and MacDonald, D M, Acta Dermatovenereologica, 1974, 54, 487.

${ }^{8}$ Sneddon, I B, British Fournal of Dermatology, 1966, 78, 649.

${ }^{9}$ Marmion, V J, Proceedings of the Royal Society of Medicine, 1969, 62, 11

${ }^{10}$ Marks, R, and Ellis, J, Lancet, 1971, 2, 1049.

11 Savin, J A, British fournal of Dermatology, 1972, 86, suppl 8, 3.

12 Borrie, P, British fournal of Dermatology, 1953, 65, 458

\section{Measuring blood pressure}

The need for a standard routine for measuring the blood pressure has been emphasised recently ${ }^{1}$ and is clearly important in the diagnosis and assessment of hypertension and in supervising treatment when more than one observer may record the findings. Differences in the methods used in different countries have also given rise to problems in evaluation of research studies. ${ }^{2}$

Mercury manometers are to be preferred to anaeroid gauges, which, though less expensive and in some ways more convenient, need frequent checks to avoid error. Whenever possible extrinsic factors tending to produce a rise in pressure should be avoided. The subject should be warm and relaxed. The blood pressure will fall to very low levels in conditions of complete relaxation, but measuring the basal pressure after a long rest $^{3}$ is usually impracticable, and the usual criteria of hypertension will not then be applicable-so that the problem of assessment is more difficult. As a practical compromise the patient should rest semirecumbent for several minutes without smoking before the blood pressure is taken.

The size of cuff to be used has given rise to some debate. Ideally, the cuff should have a width $40 \%$ of the circumference of the arm to produce even occlusion of the brachial arterytoo narrow a cuff on a fat arm gives a falsely high reading and 